\title{
Prevalence and determinants of hypertension among urban school children in the age group of 13- 17 years in, Chennai, Tamilnadu
}

\author{
Jasmine S Sundar*, S.Joseph Maria Adaikalam, S.Parameswari, Valarmarthi.S, \\ S.Kalpana, D. Shantharam \\ Department of Epidemiology, The Tamilnadu Dr. M.G.R Medical University
}

\begin{abstract}
Introduction: Hypertension is a common disease associated with high mortality and morbidity. Hypertension could have its origin in childhood and go undetected unless specially looked for during this period. With globalization bringing more lifestyle modifications, adolescents are exposed to multiple risk factors including obesity, diet, academic stress, lack of physical work apart from hereditary risk factors. Early diagnosis of hypertension is an important strategy in its control, effective treatment and prevention of complications.

Objectives: To estimate the prevalence of hypertension among school children in the age group of 13-17 years and study the determinants.

Methods: A cross-sectional survey was done among 400 adolescent students including government and private schools in the age group of 13-17 years in Chennai. Sociodemographic details, food habits, physical activity, anthropometric measurements and family history of hypertension were obtained. Blood pressure was measured at $0,5 \& 30$ minutes and average of three readings was taken as reading of the individual. Statistical analyses were done using SPSS.

Results:The prevalence of Adolescent hypertension was 21.5\%. MANOVA showed there was significant ( $p<$ 0.05) effect on gender, class of study, body mass index, waist hip ratio. Chi-square showed significant association for same variables including parent history of hypertension. The major determinants were found to be increased Body mass index and decreased physical activity (ODD's ratio $>3$ ).

Conclusion and Recommendations: Hypertension among the adolescent age group was alarmingly high; there was no difference in prevalence among government and private schools and among various types of curriculum. Awareness of hypertension was very low. There was no association with socio economic status. Periodic surveys should be done in schools to identify the "at risk" group of children and adolescents who can develop hypertension in future, so that preventive care can be provided.
\end{abstract}

Submitted Date 06 June 2013

Accepted Date: 11 June 2013

\section{Introduction}

Hypertension is a common disease associated with high morbidity and mortality. The disease is a silent threat to the health of people all over the world. It is suggested that hypertension has its origin in childhood but goes undetected unless specifically looked for during this period. Thus, early detection of hypertension and its precipitating or aggravating factors are important if one is to evolve measures so that complications of hypertension can be prevented.

Hypertensive children tend to have other medical problems, such as obesity, high blood lipids and/or diabetes mellitus. Coronary risk factors such as hypertension, smoking, physical inactivity, obesity and improper diet are fairly widespread. Cardiovascular diseases, particularly hypertension, account for high mortality in the form of cardiovascular strokes in countries like India, Taiwan and Japan ${ }^{1}$. In Indian adolescent school children, there is a high prevalence of obesity, hypertension, and hypercholesterolemia. Studies from Boston and Pennsylvania had commented that the role of hypertension as a risk factor is clear and familial aggregation of blood pressure and tracking phenomenon support the concept that children with hypertension are likely to be hypertensive as adults and will be at risk for early Coronary heart disease ${ }^{2}$.

Though the data on Adolescents hypertension is very scarce across the globe, the National High Blood Pressure Education Programme (NHBPEP) of United States has recognized the presence of primary hypertension in children and adolescents. ${ }^{3}$

With globalization bringing more lifestyle modifications, adolescents are exposed to multiple risk factors including obesity and also family history of hypertension. ${ }^{4}$ Research in this area will help policy makers to see if there is a need for addressing this problem effectively in prevention and management of hypertension in 
children and adolescents. Early diagnosis of Hypertension is an important strategy in its control, which will be useful in tracking and effective treatment, to prevent further complications. Hence study was conducted to estimate the prevalence of hypertension in Chennai city and determinants of hypertension such as obesity, family history of hypertension, physical inactivity and life style associated with adolescent hypertension.

\section{Materials and Methods}

A cross sectional study was executed in Chennai-India including 400 samples with an equal distribution of 200 each from both private and public schools. Chennai has been divided into four educational zones namely North, South, Central and East zones. From each zone one school both from public and private sector using stratified random sampling method was selected. From each school fifty adolescent students (25 boys \& 25 girls) between the age group of 13-17 who were eligible were selected by simple random sampling method and included for the study after obtaining their informed consent.

\section{Blood Pressure Measurement:}

\section{Methodology}

The Student was seated and relaxed. The cuff was placed on the right arm at the level of heart. On the day of measurement three readings were made at 0,5 and 30 minutes. The average of three readings was taken as blood pressure of the individual.

\section{Socio economic status}

Socioeconomic status of the family in which respondent belonged was recorded using a well structured questionnaire. The questionnaire included details such as Personal details: Age, religion, Standard, Type of curriculum Academic performance Family details: Type of family, Parent's education, occupation, income Physical activities: Details of physical activity in school and indoor activities Food details: details of junk food and aerated drinks and frequency of intake .

Health information: Awareness regarding hypertension such as Its definition, causes and symptoms were included. Details of the presence of symptoms of hypertension and history of parent's hypertension.

Anthropometric measurements such as height, weight, Waist-Hip ratio were

recorded. Statistical analysis was done using SPSS version 10.

Hypertension: According to Joint National Committee VII (Indian scenario),2003 12 the following measurements of blood pressure are considered as normal, pre-hypertension and hypertension.

For - 13 years

\begin{tabular}{|l|l|l|}
\hline Classification & Systolic BP mmHg & Diastolic BP mmHg \\
\hline Normal & $<120$ & $<80$ \\
\hline Pre Hypertension & $120-139$ & $80-89$ \\
\hline Stage I Hypertension & $140-159$ & $90-99$ \\
\hline Stage II Hypertension & $>160$ & $>100$ \\
\hline
\end{tabular}

\section{Results}

Adolescent Hypertension (AHTN) among school students: In this study 86 of the 400 participants were found to have hypertension. The prevalence AHTN was $21.5 \%$ and normal children were 314 (78.5\%).

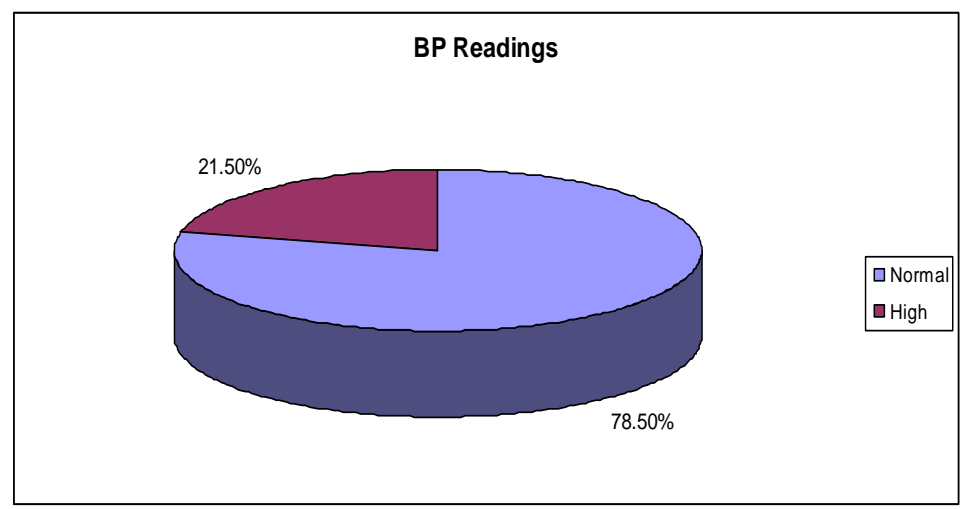

Fig-1 prevalence of Hypertension 
Both the systolic and diastolic BP was observed in 21 of these 86 hypertensives $(24.41 \%)$ whereas 65 students (75.59\%) had isolated systolic HTN. No students had isolated diastolic HTN.

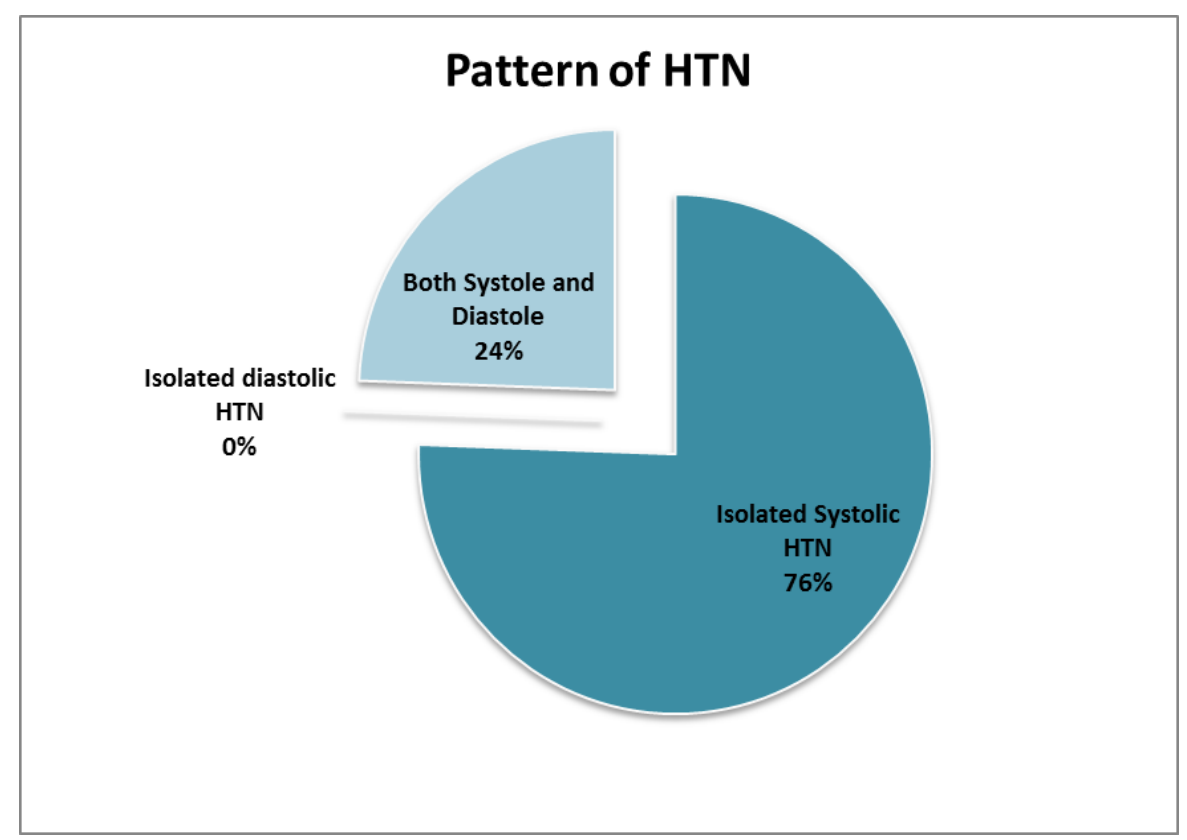

Fig: 2. Mean and standard deviation of systolic B.P was $110 \mathrm{~mm} / \mathrm{Hg}$ and 12.65, Diastolic B.P was $65 \mathrm{~mm} / \mathrm{Hg}$ and 8.62 .

Fig:3 Gender wise prevalence

\section{Genderwise Prevalence of Hypertensive}

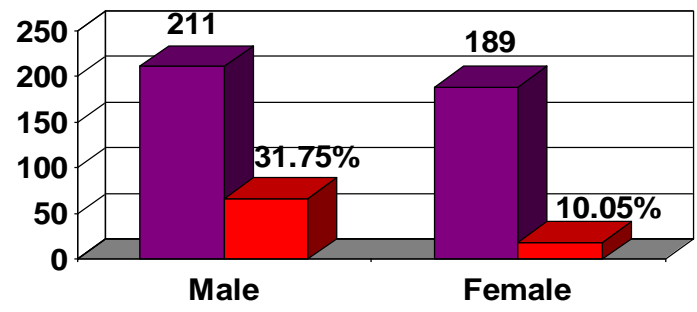

$\square$ Total $\square$ Hypertensive

The prevalence among male was 67 (77.90\%) and among females 19 (22.09\%), which was found to be highly significant among males than females $(\mathrm{p}=0.000)$.

\section{BMI and HTN}

Of the 321 normal weight students between (15th and 85th percentile), there were 53 (16.51\%) hypertensives Eighteen were underweight below 15th percentile and there were no hypertensive's among them.

Forty six were overweight with BMI between (85th and 95th percentile), $24(52.17 \%)$ students were hypertensives, fifteen were obese with BMI above 95th percentile $9(56.25 \%)$ were hypertensives. 
Fig :4

\section{BMI VS HTN}

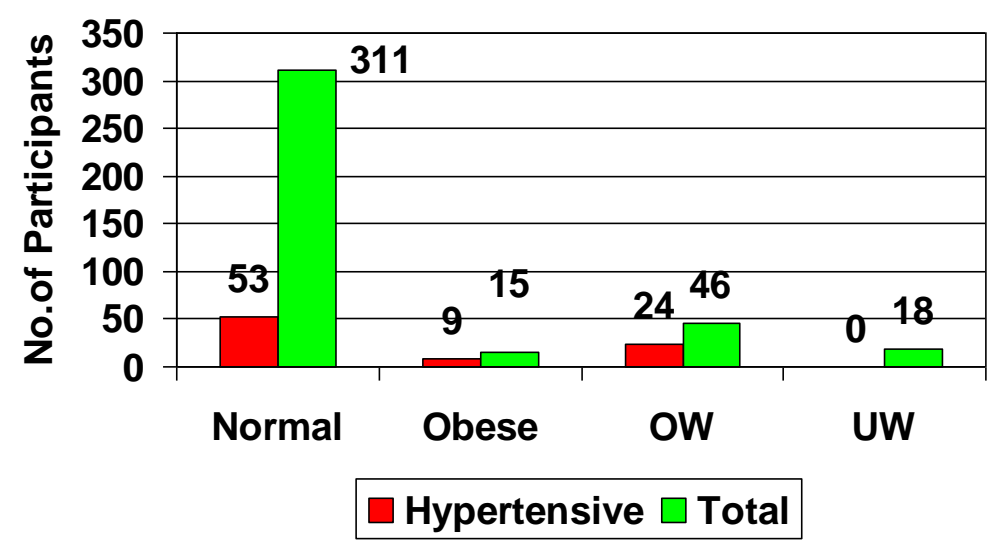

Highly significant risk factors for HTN:

Table below shows the risk factor for development of HTN in this study, gender, standard, BMI, Obesity, Waist Hip ratio and family of hypertension which were found highly significant.

\section{Multivariate Analysis}

\begin{tabular}{|l|l|l|l|l|}
\hline & $\begin{array}{l}\text { Pearson } \\
\text { Chi-Square }\end{array}$ & p value & F test & p value \\
\hline Gender & 27.818 & 0.000 & 29.747 & 0.000 \\
\hline Class & 18.723 & 0.001 & 14.797 & 0.000 \\
\hline BMI & 48.482 & 0.000 & 89.941 & 0.000 \\
\hline Obesity & 7.567 & 0.006 & 50.071 & 0.000 \\
\hline Waist Hip Ratio & 175.937 & 0.002 & 24.641 & 0.000 \\
\hline Family h/o HTN & 9.243 & 0.026 & 7.153 & 0.008 \\
\hline
\end{tabular}

\section{Other Medical Conditions:}

Out of 400 participants 386 were normal healthy individuals without taking any any medications, two $(0.5 \%)$ students were known hypertensive and on treatment. Six students were asthmatic, one had undergone coronary bypass surgery, two girls reported irregular periods and five students complained of renal calculi and epilepsy who were on treatment.

\section{v. Discussion}

Adolescent Hypertension is an emerging epidemic in India and the complications of hypertension like stroke, retinopathy, and CAD. The risk factors like obesity, family history of hypertension, Physical inactivity, academic performance, food habits and life style were studied using qualitative methods.

\section{Prevalence of Adolescent Hypertension:}

The prevalence of Adolescent hypertension was $21.5 \%$ which indicates it is major public health problem and immediate intervention is needed. It has been varying widely in different Indian studies - from 
$0.46 \%$ to $11.9 \%$.In a study conducted in 2007 among school students of Adolescent age group in Mysore the prevalence was $6.1 \%{ }^{23}$. In another study done in Shimla the prevalence was $20 \%$ (study period 2005 to 2006$)^{28 .}$

The prevalence of isolated Systolic HTN in this study was $16.3 \%$. This fact also has to be taken seriously as previous studies have shown that increase in Systolic hypertension alone itself interacts with other major risk factors such as high cholesterol and diabetes, which also increase with age, to amplify the age-related risk of cardiovascular events ${ }^{24,9}$.

\section{Gender}

The prevalence among boys $(31.75 \% \mathrm{n}=211)$ was found to be much higher than among girls $(10.05 \%, \mathrm{n}=189)$. The difference was highly significant $(\mathrm{p}=0.000)$ and goes along with the study done in Kerala in 20076. But some other previous studies revealed the gender variation to be much different. While the Mysore study $^{23}$ found no gender predilection at all, few other studies showed the prevalence high among girls ${ }^{27}$. Anyhow, the finding of the current study has to be taken as significant because the prevalence among boys is strikingly high.

\section{Standard of study:}

The prevalence of hypertension was increasing with the class of study, it was the lowest among students of VIII standard and highest among X, XI and XII students. It was also statistically very significant $(\mathrm{p}=0.001)$. Though there was no previous data available in this regard, this higher prevalence may be attributed to the high stress level among the students of X, XI and XII due to huge academic burden and responsibilities. Type of curriculum

No significant relationship between the type of curriculum followed by the students and the prevalence of hypertension $(\mathrm{p}=0.340)$ could be found. It may be taken as that irrespective of the difference in their curriculum, it seems all the students face the same level of stress.

\section{Academic performance and hypertension}

There was no significant relationship between hypertension and academic performance noticed. This may be because hypertension in its earlier stage is a silent condition without any symptoms and does not affect the studies and day to day activities of the person.

\section{Physical activity:}

Current study could not find the any significant association between physical activity and hypertension. Spending more time in physical activities plays an important role in preventing and delaying the onset of hypertension. The association between physical activity and Hypertension is an established fact. A study done by Gang $\mathrm{Hu}$ on relationship of physical activity and BMI to the risk of hypertension proved the protective effect of physical activity was observed in both sexes regardless of the level of obesity ${ }^{25}$

Anyhow the It may be perhaps due to the fact that only qualitative assessment was done. In depth analysis of the level of physical activity of the students could have revealed the association in a better way. .

\section{Parent's education, employment and income:}

Details of parents' education, employment status and income were asked, to assess the socio economic status of the family. There is no influence of SES with hypertension in this study. This is a contradiction to the result of an analysis done by Tanya M.Spruill, which says prevalence of hypertension was high among people belonging to low socio-economic status due to poor living conditions and high stress ${ }^{21}$.

Food habits: The strong relationship between hypertension and diet habits has been well proved through various studies. Still the current study does not show a statistically significant relationship between food habits and HT.This may be because only qualitative assessment of food consumption was done. Anyhow nonsignificant relationship between diet and hypertension has also been arrived in another study conducted by M.R.Savitha et al in Mysore ${ }^{25}$.

\section{Relationship between BMI and HTN:}

There is an overwhelming evidence in this study that the prevalence of HT is high among obese individuals $(\mathrm{p}=0.000)$, which is highly significant. This also confirms results of done by Jonathan et al indicated obesity and overweight has major risk factors in hypertension ${ }^{31}$. John F Hall study also showed similar finding that chronic obesity also causes marked structural changes in the kidneys that eventually leads to a loss of nephron function, further increasing the arterial pressure. This study results also coincides with an Indian study done by Ruchika et al in Delhi among school children, published in $2010,{ }^{18,11}$ 


\section{Waist-Hip Ratio and HTN:}

There is strong evidence in this study that obesity and overweight among males with waist-hip ratio more than normal is highly significant for higher prevalence of adolescent hypertension. This results agrees with similar finding of Ruchika goel et al done in Delhi, increased in HTN with high W/H ratio and also Sinaiko et al 11,27

\section{Familial history and HTN:}

The prevalence of hypertension was very high (41.86\%) among children of hypertensive parents (either father or mother or both). This study strongly supports the fact that increase in prevalence of adolescent HT is highly significant among parents with hypertension. Similar relationship was found in Sharma et al a study done among Delhi school students ${ }^{26}$

This study result also agrees with another work done by KA Jamerson et al in U.S ${ }^{19}$

\section{Awareness of HTN:}

Knowledge and awareness of hypertension are important factors in early diagnosis as well as achieving blood pressure control but the awareness of HTN was suboptimal as only $28.25 \%$ among the 400 students had some awareness about hypertension. As in general all the 86 subjects who were found to be hypertensive were absolutely asymptomatic and 2 of them were known hypertensives on medication, which further implicates the need to create knowledge and awareness among school students which is a growing public health problem.Similiar result has been observed in a study done by Alexander et al published in $2003^{28}$

\section{Limitations}

1. All variables were assessed based on qualitative data as reported by verbally by the student. There were limitations in verifying the responses.

2. Repeated examination on different occasions was not done due to time constraint.

3. All measurements were made by single observer.

4. The food habits were assessed based on frequency of consumption and responses were from the child's memory, subject to recall bias.

5. Physical activity was recorded as told by the children, no observation was done.

\section{Conclusion}

1. The prevalence of hypertension among the adolescent age group was alarmingly high.

2. Obesity, family history of HTN, gender, and increased waist/hip ratio were found to be the major determinants of Adolescent hypertension.

3. There was no association found between Physical activity and food habits.

4. The is no difference in prevalence in HTN among government, private schools and also with type of curriculum.

5. Awareness about hypertension was very low among the study participants

6. There was no association with Socio economic status and AHTN

\section{Recommendations}

1. There is a need to create awareness among school students particularly in adolescent age group regarding hypertension and its complications.

2. School authorities should organize screening programmes in school particularly for HTN

3. Parents should be educated about increasing prevalence of Adolescent hypertension.

4. Children should be educated about good life style and healthy food habits.

5. Awareness programmes should be conducted among school through Medias.

6. Parents should be educated to practice traditional and healthy dietary habits in their home.

7. Parents and teachers should be sensitized on over nutrition and the health hazards of chronic nutrition excess

8. Periodic surveys should be done in schools on adolescent hypertension and tracking of blood pressure should be done, which will us helps in identifying the "at risk" group of children and adolescents, who can develop Hypertension in future period, so that preventive care can be provided for them.

\section{References}

[1]. Cardiovascular epidemiology in the Asia-Pacific region, Geok Lin Khor PhD, Department of Nutrition and Health Sciences, Malaysia,Serdang,

[2]. Tracking of Blood Pressure Among Adolescents and Young Adults in an Urban Slum of Puducherry MB Soudarssanane et al,Indian journal of community medicine-Vol. 33, Issue 2, April 2008. 
[3]. National High Blood Pressure Education Program Working Group on High Blood Pressure in Children and Adolescents. The fourth report on the diagnosis, evaluation, and treatment of high blood pressure in children and adolescents. Pediatrics. 2004;114(2 suppl 4th report):5:555-576.

[4]. Sorof JM, Alexandrov AV, Cardwell G, Portman RJ. Carotid artery intimal-medial thickness and left ventricular hypertrophy in children with elevated blood pressure. Pediatrics. 2003;111:61-66.

[5]. McNiece KL, Poffenbarger TS, Turner JL, Franco KD, Sorof JM, Portman RJ. "Prevalence of hypertension and pre-hypertension among adolescents.'Department of Pediatrics, Division of Pediatric Nephrology and Hypertension, University of Texas-Houston, School of Medicine Journal of Pediatr. 2007 Jun; 150(6):640-4, 644..

[6]. Marit Stray-Pedersen Ragnhild M Helsing, Luz Gibbons Gabriela Cormick Turid L Holme, Torstein "Weight status and hypertension among adolescent girls in Argentina and Norway" BMC Public Health 2009

[7]. Gomes Bda M, Alves JG "Prevalence of high blood pressure and associated factors in students from public schools in Greater Metropolitan Recife, Pernambuco State, Brazil, 2006" Pubmed 2009

[8]. Manu Raj, K.R. Sundaram et al. Obesity in Indian Children: Time trends and Relationship with hypertension. The National Medical Journal of India. Vol. 20. No. 6. 2007

[9]. Mohan B, Kumar N, Aslam N et al. Prevalence of sustained hypertension and obesity in urban and rural school going children in Ludhiana. Indian Heart J 2004, July - Aug; 56 Vol (4) page 310 - 4

[10]. Anand NK, Tandon L, Prevalence of hypertension in school going children. Indian Pediatrics. ISSN, 1996, vol 3, Page 377-381

[11]. Ruchika Goel Anoop Misra Sunil K Agarwal Naval Vikram "Correlates of hypertension among urban Asian Indian adolescents" Department of Medicine, All India Institute of Medical Sciences, New Delhi,India- Archives of Disease of childhood August 2010.

[12]. 7th Joint National Committee-2003

[13]. World Health Report 2002

[14]. 12.Paul Muntner, Jiang He, Jeffrey A. Cutler, Rachel P. Wildman,Paul K. Whelton, "Trends in Blood Pressure Among Children and Adolescents" - JAMA, $2004: 291(17): 2107-2113$

[15]. LL Tin, DG Beevers and GYH Lip -Journal of Human Hypertension (2002) 16, 147-150" Systolic vs diastolic blood pressure and the burden of hypertension "

[16]. Obarzanek E, Wu CO, Cutler JA, Kavey RE, Pearson GD, Daniels SR "Prevalence and incidence of hypertension in adolescent girls"-Journal of Paediatrics, 2010 May $20157(3): 461-7,467 . e 1-5$.

[17]. .Division of Cardiovascular Sciences, National Heart, Lung, and Blood Institute, Bethesda, MD 20892-7913, USA.

[18]. The kidney,hypertension and obesity John F Hall et al from the Department of Physiology and Biophysics , The University of Mississippi Medical Center, Hypertension. American Heart Association: 2003;41:625.

[19]. Effect of home blood pressure and gender on estimates of the familial aggregation of blood pressure. The Tecumseh Blood Pressure StudyKA Jamerson, N Schork and S Julius ,Department of Internal Medicine, University of Michigan Medical School, Ann Arbor. Vol 20, 314-318, 1992 by American Heart Association

[20]. 18.Effects of the Dietary Approaches to Stop Hypertension Diet Alone and in Combination With Exercise and Caloric Restriction on Insulin Sensitivity and Lipids,James A. Blumenthal; Michael A. Babyak; Andrew Sherwoodet al Departments of Psychiatry and Behavioral Sciences, Hypertension. 2010; 55:1199-1205.

[21]. Chronic Psychosocial Stress and Hypertension, Tanya M. Spruill Published : 27 January 2010

[22]. Prevalence and distribution of cardiovascular risk factors in an urban industrial population in south India: a cross-sectional study.Kaur P, Rao TV, Sankarasubbaiyan S, Narayanan AM, Ezhil R, Rao SR, Gupte MD. J Assoc Physicians India. 2007 Nov;55:77 1-6.

[23]. Trends in hypertension epidemiology in India.Gupta R Department of Medicine, Monilek Hospital and Research Centre, Jawahar Nagar, Jaipur, India , J Hum Hypertens. 2004 Feb;18(2):73-8.

[24]. Global burden of disease - Reducing Risks, Promoting Healthy Life

[25]. Essential Hypertension in Early and Mid -Adolescence, M.R Savitha,B.Krishnamurthy et al ,Dept of Paediatrics and community medicine, Mysore,Indian Journal of Paediatrics November,2007 vol 74 pg no:4

[26]. Systolic -- Not Diastolic -- Blood-Pressure Reading Should Define Hypertension, New NIH Clinical Advisory States , ScienceDaily Izzo, UB May 8, 2000.

[27]. Relationship of Physical Activity and Body Mass Index to the Risk of Hypertension: Gang Hu; Noël C. Barengo: Department of Epidemiology and Health Promotion ,School of Public Health, University of Tampere (P.J.), American Heart Association,Finland 2004;43:25

[28]. Prevalence of Hypertension Among School Children in Shimla Avinash Sharma , Neelam Grover et al - Indira Gandhi Medical College, Shimla, Himachal Pradesh; and Department of Pediatrics, All India Institute of Medical Sciences, New Delhi,2010,vol:47 pg no :873-876.

[29]. Sinaiko AR, Hypertension in Children, NEJM, 1996; $3351968-1983$.

[30]. Patient Knowledge and Awareness of Hypertension is Suboptimal: Results From a Large Health Maintenance Organization Mark Alexander et al,Med scape today 2003

[31]. Overweight, Ethnicity, and the Prevalence of Hypertension in School-Aged Children JonathanM. Sorof, MD, Dejian Lai, PhD, Department of Pediatrics School of Public Health, Department of Biometry, University of Texas Health Science Center PEDIATRICS Vol. 113 No. 3 March 2004, pp. 475-482 Acknowledgements

[32]. Author is grateful to Dr.Mayil Vahanan Natarajan, former Vice-Chancellor and present Vice-Chancellor Dr.D.Shantaram, Registrar Dr.Jhansi Charles of The Tamilnadu Dr M.G.R Medical University for granting the permission to pursue this study.

[33]. My sincere thanks to Dr.S.Joseph Maria Adaikalam, Lecturer, Department of Epidemiology for his encouragement and guidance.

[34]. Author is thankful to Dr. Parameshwari Srijayanth, Dr. S.Kalpana, Mrs Valarmathi

[35]. for their support throughout the dissertation.

[36]. I wish to express my sincere thanks to my study participants who extended their full cooperation during this study.

[37]. My special thanks to my family and friends. 